\title{
Author Correction: Multimodal imaging analyses in patients with genetic and sporadic forms of small vessel disease
}

Ko Woon Kim, Hunki Kwon, Young-Eun Kim (D), Cindy W. Yoon, Yeo Jin Kim, Yong Bum Kim, Jong Min Lee, Won Tae Yoon $\mathbb{D}$, Hee Jin Kim, Jin San Lee, Young Kyoung Jang, Yeshin Kim,

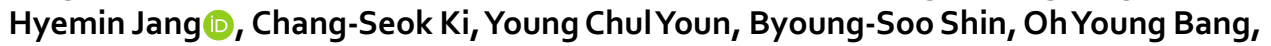
Gyeong-Moon Kim, Chin-Sang Chung, Seung Joo Kim, Duk L. Na, Marco Duering, Hanna Cho \& Sang Won Seo

Correction to: Scientific Reports https://doi.org/10.1038/s41598-018-36580-0, published online 28 January 2019

The Acknowledgements section in this Article is incomplete.

"This research was supported by a National Research Foundation of Korea (NRF) grant funded by the Korean government (MSIP) (NRF-2017R1A2B2005081); and by the Brain Research Program through the National Research Foundation of Korea (NRF) funded by the Ministry of Science, ICT, \& Future Planning (2016M3C7A1913844)."

should read:

“This research was supported by Research of Korea Centers for Disease Control and Prevention (2018-ER620301); the Brain Research Program through the National Research Foundation of Korea(NRF) funded by the Ministry of Science, ICT \& Future Planning (2016M3C7A1913844); the National Research Foundation of Korea(NRF) grant funded by the Korea government(MSIP) (NRF-2017R1A2B2005081); and a grant from the Korean Health Technology R\&D Project, Ministry of Health \& Welfare, Republic of Korea(HI18C1629)."

(c) (1) Open Access This article is licensed under a Creative Commons Attribution 4.0 International Cicense, which permits use, sharing, adaptation, distribution and reproduction in any medium or format, as long as you give appropriate credit to the original author(s) and the source, provide a link to the Creative Commons license, and indicate if changes were made. The images or other third party material in this article are included in the article's Creative Commons license, unless indicated otherwise in a credit line to the material. If material is not included in the article's Creative Commons license and your intended use is not permitted by statutory regulation or exceeds the permitted use, you will need to obtain permission directly from the copyright holder. To view a copy of this license, visit http://creativecommons.org/licenses/by/4.0/.

(C) The Author(s) 2019 